\title{
Raw Starch-digestive Glucoamylase Productivity of Protease-less Mutant from Aspergillus awamori var. kawachi
}

\author{
Shinsaku Hayashida and Perfecto Q. Flor \\ Department of Agricultural Chemistry, Kyushu University, \\ Fukuoka 812, Japan
}

Received May 26, 1980

\begin{abstract}
Mutation experiments were performed to decrease the protease productivity of Aspergillus awamori var. kawachi using ultraviolet light and $N$-methyl- $N^{\prime}$-nitro- $N$-nitrosoguanidine. The selected mutant HF- 15 showed reductions in protease productivity of $93 \%, 84 \%$ and $50 \%$ in solid wheat bran culture, shaking Medium B and wheat bran cultures, respectively, as compared with the parent. Protease-less mutant HF-15 failed to produce $\alpha$-mannosidase, and $N$-acetyl- $\beta$-Dglucosaminidase productivity decreased by $35 \%$. Mutant HF-15 specifically produced a high amount of raw starch-adsorbable and raw starch-digestive glucoamylase similar to GA I under all tested cultural conditions. On the contrary, high protease-producing mutant HF-10 produced a glucoamylase with very limited adsorption and digestion capacity on raw corn starch, and lower hydrolysis toward gelatinized potato starch and glycogen that was similar to GA I'.
\end{abstract}

A number of reports have appeared on the influence of environmental conditions on the submerged culture production of glucoamylase by molds. Aspergillus awamori var. kawachi was reported to produce three types of glucoamylase on a mold bran culture, ${ }^{1)}$ designated as glucoamylase (GA) I, I' and II. The mold also selectively produced these three types of glucoamylase under the defined cultural conditions, A, B and $\mathrm{C}^{2)}$ The raw starchdigestive GA I was stepwisely degraded with proteases and glycosidases to GA I' and GA II by in vitro experiments. The latter two glucoamylases had lower molecular weights, different hydrolysis curves for gelatinized potato starch and glycogen, and no ability to digest raw starch or to be adsorbed onto raw corn starch. ${ }^{3 \sim 5}$ Furthermore, a mechanism for the formation of multiple types and forms of glucoamylase was proposed. ${ }^{5}$ On the basis of these results, there seemed to be no doubt that the presence of high activities of proteases and glycosidases in the culture during the submerged production of glucoamylase by $A$. awamori var. kawachi alters the enzymatic properties of GA I, and leads to the formation of multiple types and forms of glucoamylase. Selection of a mutant which has lost almost all the ability to produce proteases and glycosidases but retained that of high productivity of raw starch-digestive GA I would therefore be important from the viewpoint of commercial production of glucoamylase.

In this paper, the isolation and glucoamylase productivity of the protease-less mutant from $A$. awamori var. kawachi are presented. A mutant that produced a higher amount of protease than the parent is also presented for comparison.

\section{MATERIALS AND METHODS}

Induction and isolation of mutants. Aspergillus awamori var. kawachi was used as parent material. After a number of preliminary trials, the following general procedure was established. The parent culture was grown on a slant of complete medium (glucose, $10 \mathrm{~g}$; peptone, $5 \mathrm{~g}$; yeast extract, $5 \mathrm{~g}$; malt extract, $3 \mathrm{~g} ; \mathrm{K}_{2} \mathrm{HPO}_{4}, 1 \mathrm{~g}$; agar, $20 \mathrm{~g}$; deionized water, $1000 \mathrm{ml}$ ) for 10 days at $30^{\circ} \mathrm{C}$. The spores were collected and suspended in sterile water to give a spore suspension of not less than $10^{8}$ spores $/ \mathrm{ml}$. Ten $\mathrm{ml}$ of the spore suspension was treated with $10 \mathrm{ml}$ of freshly prepared $N$-methyl- $N^{\prime}$-nitro- $N$-nitrosoguanidine (MNNG) at a concentration of $4 \mathrm{mg} / \mathrm{ml}$ in $0.1 \mathrm{M}$ acetate 
buffer, $\mathrm{pH} 4.5$ for $20 \mathrm{~min}$ in sterilized tubes and then centrifuged for $5 \mathrm{~min}$ to remove the supernatant. The precipitated spores were washed once with sterile water and then inoculated into $100 \mathrm{ml}$ of sterile minimal medium (glucose, $50 \mathrm{~g} ; \mathrm{NaNO}_{3}, 3 \mathrm{~g} ; \mathrm{KH}_{2} \mathrm{PO}_{4}, 1 \mathrm{~g} ; \mathrm{KCl}, 0.5 \mathrm{~g}$; $\mathrm{MgSO}_{4} \cdot 7 \mathrm{H}_{2} \mathrm{O}, 0.2 \mathrm{~g} ; \mathrm{FeSO}_{4} \cdot 7 \mathrm{H}_{2} \mathrm{O}, 0.01 \mathrm{~g} ;$ deionized water, $1000 \mathrm{ml}$ ) and shaken at $30^{\circ} \mathrm{C}$ for $36 \mathrm{hr}$. The mycelia were separated by filtration through sterile glass wool and the filtrate was plated onto the complete medium, and incubated at $30^{\circ} \mathrm{C}$ for 7 to 10 days. Colonies were transferred to complete medium slants and further incubated at $30^{\circ} \mathrm{C}$ for 7 to 10 days. Several transfers were done to test the stability of the mutants. The selected mutants were plated individually onto casein medium (casein purchased from Wako Pure Chemical Industries $\mathrm{Ltd}, 5 \mathrm{~g}$; casamino acid, $0.05 \mathrm{~g} ; \mathrm{Na}_{2} \mathrm{HPO}_{4} \cdot 7 \mathrm{H}_{2} \mathrm{O}, 1.07 \mathrm{~g}$; $\mathrm{KH}_{2} \mathrm{PO}_{4}, 0.36 \mathrm{~g} ; \mathrm{MgSO}_{4} \cdot 7 \mathrm{H}_{2} \mathrm{O}, 0.5 \mathrm{~g} ; \mathrm{NaCl}, 0.1 \mathrm{~g} ; \mathrm{ZnCl}_{2}$, $0.14 \mathrm{~g} ; \mathrm{CaCl}_{2} \cdot \mathrm{H}_{2} \mathrm{O}, 0.002 \mathrm{~g} ; \mathrm{FeSO}_{4} \cdot 7 \mathrm{H}_{2} \mathrm{O}, 0.002 \mathrm{~g}$; agar, $20 \mathrm{~g}$; deionized water, $1000 \mathrm{ml}$ ) for primary screening for protease productivity. Mutants with significantly large and small halos (clear zones) as compared with the parent were selected, and cultured in potato dextrose agar medium for 10 days at $30^{\circ} \mathrm{C}$. Spores of the selected mutants were inoculated into solid wheat bran medium and liquid synthetic Medium B as previously reported ${ }^{2}$ with slight modification (Table I). This synthetic medium was found to induce high protease production during the submerged culture production of glucoamylase. Mutants with significantly low and high protease activities in solid wheat bran culture were selected and further subjected to the combined action of MNNG and UV treatments. Spores of these selected mutants were further suspended in $0.2 \mathrm{M}$ citrate buffer, $\mathrm{pH} 4.5$, to give a spore suspension of not less than $10^{8}$ spores $/ \mathrm{ml}$. Ten $\mathrm{ml}$ from each suspension was added to $10 \mathrm{ml}$ of the freshly prepared MNNG $(2 \mathrm{mg} / \mathrm{ml})$ solution and dispensed individually into sterile petridishes and then immediately exposed to a 15 watt UV lamp at a distance of around $36 \mathrm{~cm}$ for $20 \mathrm{~min}$ with continuous stirring with a sterile magnetic stirrer. The suspensions were serially diluted with sterile water and individually plated onto complete medium slants and further incubated at $30^{\circ} \mathrm{C}$ for 7 to 10 days. The isolates were further plated onto complete medium to assess their stability. The stable mutants were again further tested for their ability to produce protease in solid wheat bran culture and liquid synthetic Medium $\mathrm{B}$ for final selection. All mutants were maintained in glucose peptone yeast extract agar medium (glucose, $50 \mathrm{~g}$; peptone, $5 \mathrm{~g}$; yeast extract, $3 \mathrm{~g} ; \mathrm{K}_{2} \mathrm{HPO}_{4}, 1 \mathrm{~g}$; agar, $20 \mathrm{~g}$; deionized water, $1000 \mathrm{ml}$ ) and stored at $4^{\circ} \mathrm{C}$.

Cultures of mutants. The selected mutants were grown on potato dextrose agar slants for 10 days and the spores were collected, inoculated into $100 \mathrm{ml}$ of liquid synthetic Medium B, and cultured with shaking for 5 days at $30^{\circ} \mathrm{C}$. Samples were taken every six hours for assay of protease, glucoamylase, and glycosidase activities. To test the activities of protease and glucoamylase produced by the mutants in solid wheat bran culture, spores were inoculated into freshly prepared wheat bran medium and incubated for 5 days at $30^{\circ} \mathrm{C}$. The enzymes were extracted by the addition of $150 \mathrm{ml}$ tap water and $5 \mathrm{ml}$ toluene, and then left to stand at room temperature for $5 \mathrm{hr}$ before filtration. In the case of the shaking wheat bran culture, spores were inoculated into the freshly prepared medium (Table I), shaken for 3 days at $30^{\circ} \mathrm{C}$ and then the filtrate was collected and tested for enzyme activities.

Assay of glycosidase activity. The procedures proposed by Mega et al $^{6)}$ for $N$-acetyl- $\beta$-D-glucosaminidase activity and Paus and Christensen ${ }^{7 /}$ for $\alpha$-mannosidase activity were used with slight modifications. $p$-Nitrophenyl- $\beta$ D-mannoside and $p$-nitrophenyl- $N$-acetyl- $\beta$-D-glucosaminide, both purchased from Sigma Chemical Co.

Table I. Composition of Culture Media for Enzyme Production

\section{Synthetic Medium B}

Potato starch

Ammonium acetate

Potassium phosphate

(monobasic)

Magnesium sulphate

Sodium chloride

Calcium chloride

Adjust $\mathrm{pH}$ to 7.0 with $28 \%$ ammonium hydroxide

$\begin{array}{lr}\text { Ferrous sulphate } & 1 \mathrm{mg} \\ \text { Zinc sulphate } & 0.5 \mathrm{~g} \\ \text { Manganese sulphate } & 1 \mathrm{mg} \\ & \\ \text { Cobalt sulphate } & 10 \mu \mathrm{g} \\ \text { Copper sulphate } & 10 \mu \mathrm{g} \\ \text { Tap water } & 1000 \mathrm{ml}\end{array}$

$1 \mathrm{mg}$

$10 \mu \mathrm{g}$

$000 \mathrm{ml}$

Solid Wheat Bran Culture

Wheat bran

$25 \mathrm{~g}$

Ammonium citrate

$0.5 \mathrm{~g}$

Rice hull

Suspended Wheat Bran Culture

Wheat bran

Rice bran

$0.5 \mathrm{~g}$

Ammonium citrate

Tap water

$100 \mathrm{ml}$ 
were used as substrate for the assay of $\alpha$-mannosidase and $N$-acetyl- $\beta$-D-glucosaminidase, respectively. The incubation mixture contained $0.1 \mathrm{ml}$ enzyme and $0.9 \mathrm{ml}$ of $0.01 \%$ substrate in citrate buffer, $\mathrm{pH} 4.3$ : The mixtures were incubated at $37^{\circ} \mathrm{C}$ for $30 \mathrm{~min}$ and then $2 \mathrm{ml}$ of $0.25 \mathrm{M}$ sodium carbonate was added to the mixture. The $p$-nitrophenol liberated was determined spectrophotometrically at $400 \mathrm{~nm}$. One unit of enzyme activity was defined as the amount of enzyme that liberated $1 \mu \mathrm{mol} p$ nitrophenol per min under the above conditions.

Assay of proteases. Protease activity was determined by incubating $1 \mathrm{ml}$ of enzyme solution with $5 \mathrm{ml}$ of $1.2 \%$ Hammarsten's casein (buffered at pH 3,7 and 9 for acid, neutral and alkaline proteases, respectively) for $10 \mathrm{~min}$. One unit of protease activity was defined as that which produced $1 \gamma$ of tyrosine per minute at $30^{\circ} \mathrm{C}$, measured by Folin's procedure.

Assay of amylases. Amylase activity was determined by incubating $1 \mathrm{ml}$ of enzyme solution with $5 \mathrm{ml}$ of $1 \%$ gelatinized potato starch solution (Japanese Pharmacopoeia), $1 \mathrm{ml}$ of Mcllvaine buffer, $\mathrm{pH} \mathrm{3.8,} \mathrm{and}$ $1 \mathrm{ml}$ of pure water at $50^{\circ} \mathrm{C}$. For assay of $\alpha$-amylase, $0.1 \mathrm{ml}$ of the reaction mixture was taken at intervals, and added to $1 \mathrm{ml}$ of $0.01 \mathrm{~N}$ iodine solution. The change in color was observed, and the time required for the erythro point was determined. One unit of $\alpha$-amylase activity was defined as that which converted starch to the erythro point in 100 min under the above conditions. For glucoamylase, $1 \mathrm{ml}$ of the reaction mixture as above was taken after incubation for $10 \mathrm{~min}$ or so, reducing sugar formed was determined by the micro-Bertrand method and the degree of hydrolysis was calculated as the percentage of theoretical glucose for the hydrolysis curve. One unit of glucoamylase activity was defined as that with which $1 \mathrm{mg}$ of glucose was produced in $1 \mathrm{ml}$ of the above reaction mixture in $100 \mathrm{~min}$ under the above conditions.

Adsorption rate of glucoamylase onto raw corn starch. A desired amount of culture filtrate was added to $0.02 \mathrm{M}$ citrate buffer, pH 3.6, to prepare an enzyme solution with glucoamylase activity of $10 \mathrm{U} / \mathrm{ml}$. One gram of raw corn starch (Japanese Pharmacopoeia) was added to $5 \mathrm{ml}$ of the prepared enzyme solution and left to stand at $4{ }^{\circ} \mathrm{C}$ for 15 min. After centrifugation, amylase activity of the supernatant fluid was assayed, and compared with that of the original amylase solution. The adsorption rate $(A R)$ is defined according to the equation:

$$
A R(\%)=\frac{(B)-(A)}{(B)} \times 100
$$

where $(A)$ indicates the residual amylase activity after the adsorption test and $(B)$ that of the original enzyme solution.
Determination of raw starch digestion. A reaction mixture, which contained 0.3 grams of raw corn starch, $36 \mathrm{ml}$ of pure water, $6 \mathrm{ml}$ of $0.1 \mathrm{M}$ citrate buffer of $\mathrm{pH} 3.6$ and $6 \mathrm{ml}$ of culture filtrate $(15 \mathrm{U} / \mathrm{ml})$ with $1 \mathrm{ml}$ of toluene, was incubated at $30^{\circ} \mathrm{C}$. At suitable intervals, reducing sugar formed in $1 \mathrm{ml}$ of the reaction mixture was determined by the micro-Bertrand method and the degree of hydrolysis was calculated.

\section{RESULTS}

\section{Selection of mutants}

At first, 110 mutant clones were tested for their ability to produce halos (clear zones) in casein medium. Only 14 isolates were selected on the basis of higher and lower ratios of diameter of the halo to that of the colony on the casein medium. These isolates were further tested for their ability to produce protease and glucoamylase in solid wheat bran medium. One clone exhibiting the lowest protease productivity was selected and further exposed to combined MNNG and UV treatments. As a result, 25 clones were isolated. One clone with significantly very low protease activity in both casein and solid wheat bran medium was selected and designated as protease-less mutant HF-15. On the other hand, a mutant which showed the ability to produce a high amount of protease in wheat bran medium was used for comparison, and was designated as mutant $\mathrm{HF}-10$. Unless otherwise indicated, protease mentioned in the text refers to acid protease.

\section{Morphological characteristics of protease-less mutant HF-15 \\ Differences in conidia formation between} the mutant and parent are shown in Fig. 1. The protease-less mutant, HF-15, produced smaller conidia as compared with the parent strain. Park and De Santi ${ }^{8)}$ also successfully isolated a high amyloglucosidase and low transglucosidase producing mutant of Aspergillus awamori with smaller and retarded conidia.

\section{Enzyme productivity of mutants in solid culture on wheat bran medium}

The protease productivity of mutant $\mathrm{HF}-15$ was significantly decreased by $93 \%$, whereas 


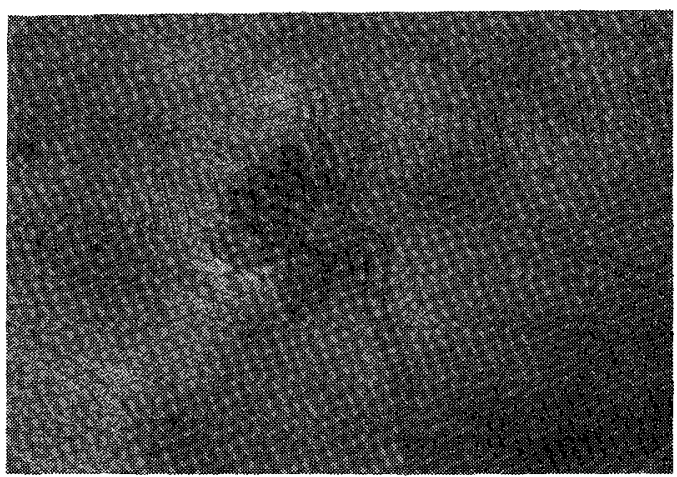

(A)

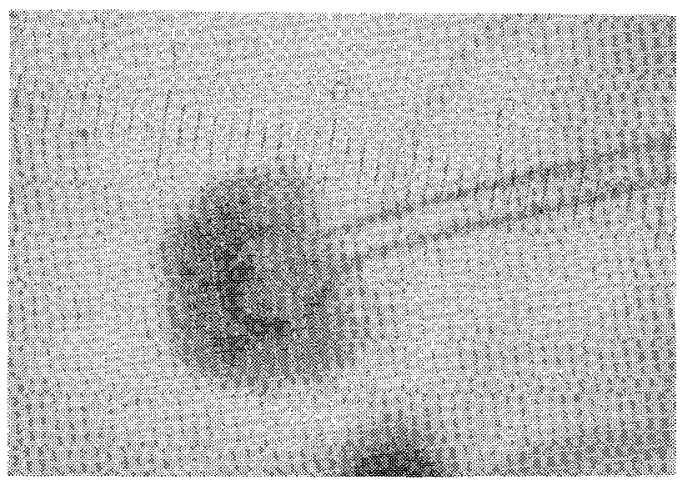

(B)

FIG. 1. Microphotographs of Conidia of (A), Mutant HF-15, and (B), Parent.

the protease productivity of mutant $\mathrm{HF}-10$ increased five-fold in comparison with that of the parent. Glucoamylase productivities of both mutants and parent were almost the same but their adsorption rates onto raw corn starch were completely different. The adsorption rate of the glucoamylase of mutant HF15 was around $85 \%$ whereas those of the parent and mutant $\mathrm{HF}-10$ were around $42 \%$ and $5 \%$, respectively. The differences in the adsorption rates among the mutants and parent indicated that they produced different amounts of the raw starch-adsorbable, raw starch-digestive glucoamylase.

\section{Enzyme productivity of mutants on submerged} culture in a wheat bran medium

The properties of glucoamylases produced by the mutants were further investigated under submerged conditions with wheat bran as

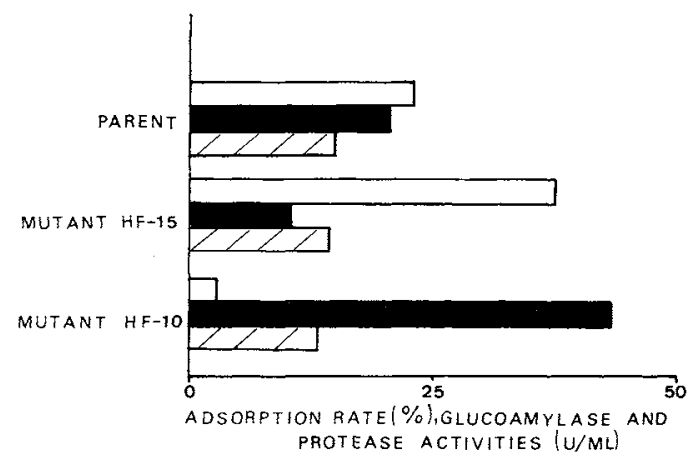

Fig. 2. Enzyme Productivity of Mutants on Submerged Culture in a Suspension of Wheat Bran after 3 Days Incubation, and Their Respective Glucoamylase Adsorption Rates onto Raw Corn Starch.

II , adsorption rate $(\%), \mathrm{pH} 3.6 ; \mathbf{N}$, acid protease activity $(\mathrm{U} / \mathrm{ml}) ; \square]$, glucoamylase activity $(\mathrm{U} / \mathrm{ml})$. The experimental details are given in the text.

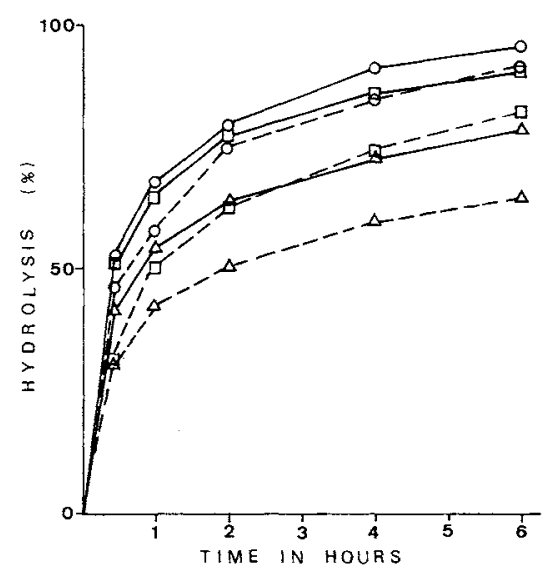

FIG. 3. Hydrolysis Curves for Potato Starch and Glycogen with the Suspended Wheat Bran Culture Filtrates of Mutants and Parent.

-, potato starch; ---, glycogen; $\mathrm{O}$, mutant HF-15; $\triangle \mathrm{mu-}$ tant HF-10; $\square$, parent.

One $\mathrm{ml}$ of the culture filtrate with the glucoamylase activity adjusted to 15 units was incubated with $100 \mathrm{mg}$ cooked potato starch or glycogen in $7 \mathrm{ml} 0.02 \mathrm{M}$ acetate buffer, $\mathrm{pH} 4.2$, at $40^{\circ} \mathrm{C}$. The $\alpha$-amylase activities of the culture filtrates of mutant HF-15, mutant HF-10 and parent were $22.2,10$, and 20 units per $\mathrm{ml}$, respectively.

natural organic medium. As shown in Fig. 2, the culture filtrate of mutant HF-15 exhibited the lowest protease activity and highest raw corn starch adsorbability. The hydrolysis curves for gelatinized potato starch and glycogen with the culture filtrates of mutants and 


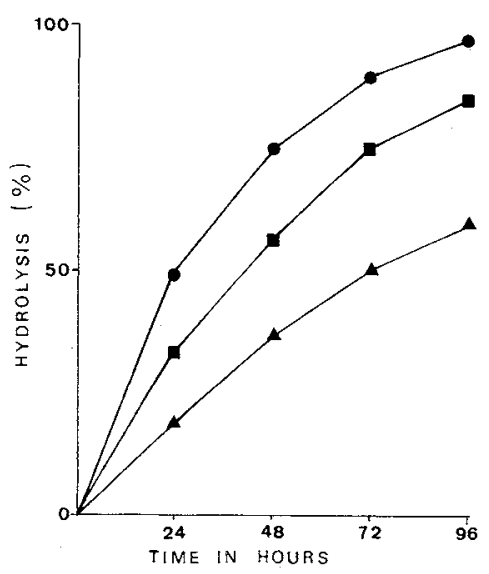

FIG. 4. Raw Corn Starch Digestion by the Suspended Wheat Bran Culture Filtrates of Mutants and Parent.

- - - mutant HF-15; - $\mathbf{A}-$, mutant HF-10; - $\mathbf{-}-$, parent.

The experimental details are given in the text.

parent are shown in Fig. 3. The culture filtrate of mutant HF-15 showed a higher extent of percent hydrolysis not only toward gelatinized potato starch and glycogen but also raw corn starch, as shown in Fig. 4. The protease productivity of mutant HF-15 decreased by about $50 \%$ as compared with that of the parent.

\section{Enzyme productivity of mutants on submerged culture in synthetic Medium B}

The mutants were further tested for their ability to produce GA I in the Medium B previously reported ${ }^{2)}$ to induce the production of a raw starch-indigestive GA I'. The mutants were grown in slightly modified synthetic Medium B and the time courses of enzyme production are shown in Figs. 5 and 6 . In the case of mutant HF-15, the peak of glucoamylase activity was observed at $96 \mathrm{hr}$, whereas for the parent it was $84 \mathrm{hr}$ (Fig. 5). The glucoamylase productivity of the mutant increased by about $65 \%$ in comparison with the parent. The protease productivity of the mutant decreased by $84 \%$. Neither neutral nor alkaline protease was observed in the mutant culture filtrate. The mutant showed no $\alpha$ mannosidase activity throughout the culture period and there was a $35 \%$ reduction in $N$ -

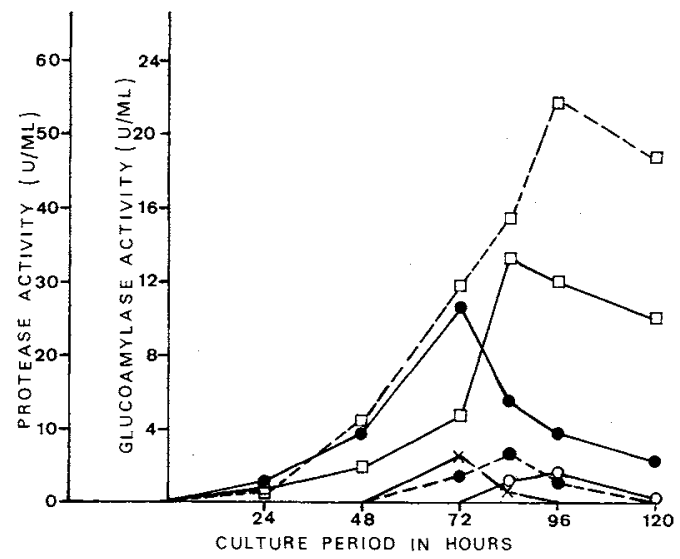

Frg. 5. Time Courses of Glucoamylase and Protease Production of Mutant HF-15 and Parent Strain in Liquid Synthetic Medium B.

$\square$, glucoamylase activity; - acid protease; $\times$, neutral protease; $\bigcirc$, alkaline protease; --., mutant HF-15; parent.

Experimental details are given in the text.

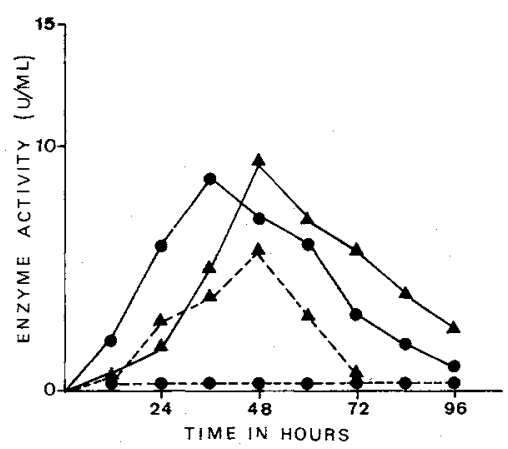

FIG. 6. Glycosidase Production of Mutant HF-15 and Parent Strain in Liquid Synthetic Medium B.

- $\alpha$-mannosidase; $\boldsymbol{\Lambda}, N$-acetyl- $\beta$-D-glucosaminidase; ---, mutant HF-15; - , parent.

acetyl- $\beta$-D-glucosaminidase activity (Fig. 6).

On the other hand, mutant HF-10 exhibited comparatively poor growth in synthetic Medium B and as a result, lower glucoamylase and protease activities in the culture filtrate were observed. In addition, slight neutral protease activity was detected, and the $N$-acetyl- $\beta$ D-glucosaminidase increased by two-fold, but its $\alpha$-mannosidase activity decreased by about $60 \%$, as compared with that of the parent. 


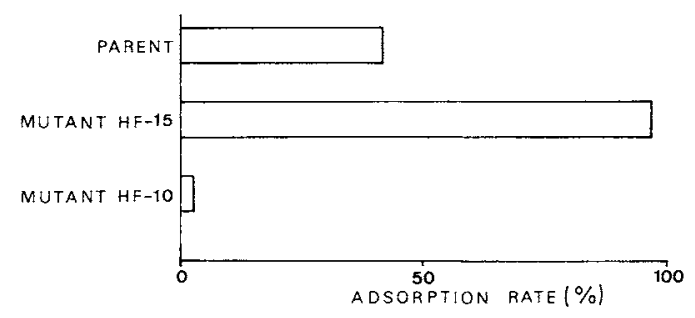

FIG. 7. Raw Corn Starch Adsorption of Glucoamylases Produced by Mutants and Parent in Synthetic Medium B.

Experimental details are given in the text.

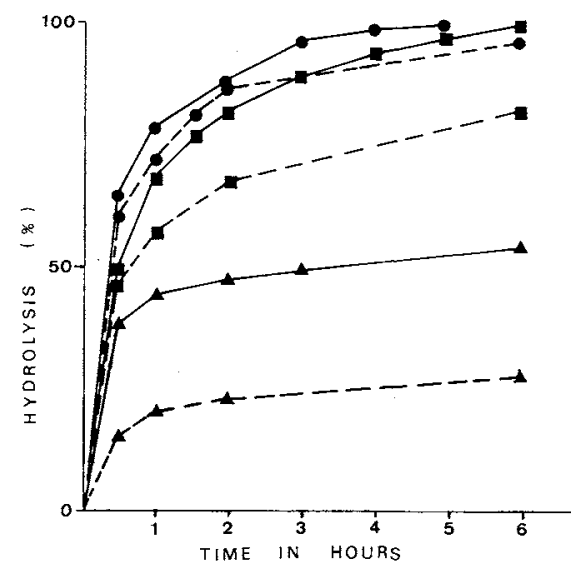

Frg. 8. Hydrolysis Curves for Potato Starch and Glycogen with the Synthetic Medium B Culture Filtrates of Mutants and Parent.

-, potato starch; -.., glycogen; - mutant HF-15; mutant HF-10; $\mathbf{\square}$, parent.

The reaction mixture was the same as in Fig. 3. The $\alpha$ amylase activities of mutant $\mathrm{HF}-15$, mutant $\mathrm{HF}-10$ and parent were 25,7 and 25 units per $\mathrm{ml}$, respectively.

\section{Hydrolysis of various substrates}

The mutants and the parent were cultured in synthetic Medium B, shaken for $84 \mathrm{hr}$ at $30^{\circ} \mathrm{C}$, and then their respective filtrates were collected as enzymes solutions throughout the experiment. For adsorption tests, the glucoamylase activities of the culture filtrates of mutants and the parent were adjusted to an activity of $10 \mathrm{U} / \mathrm{ml}$. As shown in Fig. 7, the glucoamylase from mutant $\mathrm{HF}-15$ was adsorbed intensively onto raw corn starch, whereas the adsorption rate of the glucoamylase from mutant HF-10 was very low. Furthermore, the glucoamylase from mutant HF-15 hydrolyzed gelatinized potato starch,

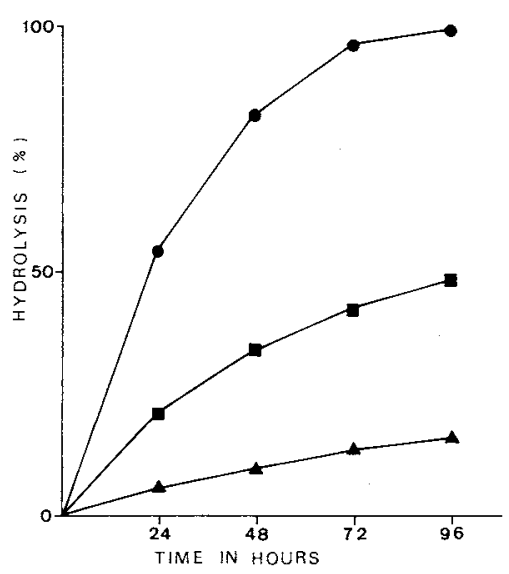

FIG. 9. Raw Corn Starch Digestion by the Synthetic Medium B Culture Filtrates of Mutants and Parent

- - , mutant HF-15; - - , mutant HF-10; - $\mathbf{-}-$, parent.

Experimental details are given in the text.

glycogen and raw corn starch to a high extent as compared with the glucoamylases of mutant HF-10 and parent (Figs. 8 and 9).

\section{DISCUSSION}

The multiplicity of glucoamylases from Aspergillus awamori var. kawachi was ascribed to the modification of the original glucoamylase GA I by proteases and glycosidases. $^{4,5}$ We therefore tried to isolate a mutant that could produce a limited amount of proteases in any of the cultural conditions tested, for the purpose of selective production of the original type or prototype of raw starchdigestive glucoamylase. This paper reports that the glucoamylase of the isolated proteaseless mutant HF-15 showed significantly higher degrees of adsorbability onto raw corn starch and digestibility of raw starches, as compared with the glucoamylases produced by high protease-producing mutant $\mathrm{HF}-10$ and the parent strain, just as we had expected. Mutant HF-15 was suggested to be useful for the selective submerged production of the raw starch-digestive glucoamylase. The production of a high amount of raw starch-digestive glucoamylase by mutant HF-15 could be attributed to its low productivity of proteases and glycosidases, as the enzyme was protected 
from limited proteolysis. ${ }^{3 \sim 5}$ On the contrary, the glucoamylase of the high proteaseproducing mutant, HF-10, exhibited very low extents of adsorption onto raw corn starch and of hydrolysis toward gelatinized potato starch and glycogen, similar to those of GA I'previously reported. ${ }^{4,5)}$ This implied that the glucoamylase of mutant HF-10 was modified by proteolysis as reported in previous papers. $^{2 \sim 5)}$

The present study clearly showed that a higher amount of raw starch-digestive glucoamylase was selectively produced not only by control of cultural conditions ${ }^{2}$ but also by the selection of a protease-less mutant in any uncontrolled cultural conditions. The purification and some properties of the raw starchdigestive glucoamylase produced by the mu- tant HF-15 will be reported in the following paper.

\section{REFERENCES}

1) S. Hayashida, Amylase Symposium, 1965, p. 98; Abstracts of Papers, 14th Symposium in Enzyme Chemistry, Fukuoka, May, 1962, p. 16.

2) S. Hayashida, Agric. Biol. Chem., 39, 2093 (1975).

3) S. Hayashida, T. Nomura, E. Yoshino and M. Hongo, Agric. Biol. Chem., 40, 141 (1976).

4) S. Hayashida and E. Yoshino, Agric. Biol. Chem., 42, 927 (1978).

5) E. Yoshino and S. Hayashida, J. Ferment. Technol., 56, 28 (1978).

6) T. Mega, T. Ikenaka and Y. Matsushima, $J$. Biochem., 68, 109 (1970).

7) Elizabeth Paus and T. B. Christensen, Eur. J. Biochem., 25, 308 (1972).

8) Y. K. Park and M. Silva S. De Santi, J. Ferment. Technol., 55, 193 (1977). 